\title{
Study on Treatment of High Chromium Industrial Wastewater by Pulsed Field- Coprecipitation Method
}

\author{
Jianming LIU, Juan WANG, Shu ZHANG \\ Yunnan University \\ Kunming, Yunnan, China \\ e-mail:Ljm120140@163.com
}

\begin{abstract}
Chromium pollution poses a serious threat to the safety of human beings and animals. The traditional method of treating Chromium-containing wastewater is difficult to achieve the purpose of removing chromium depth, In this paper, the removal of chromium in high-chromium industrial wastewater was studied by pulsed electric field-coprecipitation method, and the removal efficiency of chromium was explored in action time, pulse voltage and duty cycle. The experimental results show that the action time is $4 \mathrm{~min}$, the pulse voltage is $75 \mathrm{~V}$, the duty ratio is $10 \%$, and the content of chromium is reduced from $34.9 \mathrm{mg} / \mathrm{L}$ to $0.0028 \mathrm{mg} / \mathrm{L}$ Chromium removal rate of up to $99.92 \%$.
\end{abstract}

Keywords- pulsed electric field; coprecipitation; chromium; high chromium wastewater

\section{INTRODUCTION}

Chromium-containing wastewater generated in the electroplating industry is one of the most serious hazards ${ }^{[1]}$, the main forms of chromium in water are $\mathrm{Cr}^{6+}$ and $\mathrm{Cr}^{3+}$, in which the toxicity of $\mathrm{Cr}^{6+}$ is 100 times that of $\mathrm{Cr}^{3+[2]} \cdot \mathrm{Cr}^{6+}$ directly affect the body's oxidation, hydrolysis and other metabolic processes ${ }^{[3]}$. When the $\mathrm{Cr}^{6+}$ intake of more than $0.1 \mathrm{mg} / \mathrm{L}$ will lead to human poisoning ${ }^{[4]}$, long-term exposure to chromium solution, containing lead to dermatitis, eczema, "chromium sores" [5-8]. The traditional methods on the treatment of chromium containing wastewater with Precipitation, adsorption, etc ${ }^{[9-10]}$. However, these methods are difficult to reduce the total chromium content to 1.5 $\mathrm{mg} / \mathrm{L}^{[11]}$, the emission concentration higher than the national emission standard $1 \mathrm{mg} / \mathrm{L}$, can't achieve the purpose of deep chromium removal. In order to find out the effective and efficient method of removing chromium, this paper uses pulsed electric field-coprecipitation method to treat the high chromium industrial wastewater, and explores the best chrome removal efficiency in the action time, pulse voltage and duty cycle.

\section{EXPERIMENTAL STUDY ON THE TREATMENT OF High Chromium INDUSTRIAL WASTEWATER B y PULSED ELECTRIC FIELD-COPRECIPITATION METHODE}

Pulsed electric field-coprecipitation method is the application of pulsed electric field in the high chromium industrial wastewater, so that $\mathrm{Cr}^{6+}$ anion clusters in the positive plate aggregation, under the action of reducing agent $\mathrm{Cr}^{6+}$ is restored. Formation of insoluble $\mathrm{Cr}(\mathrm{OH})_{3}$ precipitates from water. At the same time, The $\mathrm{Fe}(\mathrm{OH})_{3}$ floc formed adsorbent during the reduction. Coprecipitation is an integrated precipitation process. During the process of polymer precipitation, chromium can be precipitated with the hydrolyzate by adsorption, encapsulation and complexation. The chemical precipitation and physical adsorption precipitation interaction method known as the pulse electric field - coprecipitation method.

The time of action is an important electric field parameter of pulsed electric field-coprecipitation method. The effect of different working time on the removal rate of chromium in industrial wastewater has a direct impact.

\section{A. The Effect of Different Action Time on the Efficiency of Chromium Removal}

Water samples taken from a electroplating factory production wastewater, $\mathrm{pH}$ at about 6 , the initial total chromium concentration of $34.9 \mathrm{mg} / \mathrm{L}$. Selection of $\mathrm{Cu}, \mathrm{C}$ material as a positive and negative plates.

Take $1 \mathrm{~L}$ of water sample, adjust the $\mathrm{pH}$ to $3-4$, and into the reaction tank. adjust the pulse voltage of $100 \mathrm{~V}$, pulse width of $3 \mathrm{~ms}$, period of $30 \mathrm{~ms}$, the plate spacing of $20 \mathrm{~cm}$. The action time was set to $2 \mathrm{~min}, 4 \mathrm{~min}, 6 \mathrm{~min}, 8 \mathrm{~min}, 10$ min, $30 \mathrm{~min}$ and $60 \mathrm{~min}$, respectively, After 30 seconds of electrification, and the samples were detected by the addition of $\mathrm{FeSO}_{4} \cdot 7 \mathrm{H}_{2} \mathrm{O}$ solution at the ratio of $m_{\mathrm{FeSO}_{4} \cdot 7 \mathrm{H}_{2} \mathrm{O}}: m_{\mathrm{Cr}^{6+}}=1: 1$. Sampling inspection. See Table I, Figure 1. 
TABLE I. EFFECT OF ACTION TIME ON REMOVAL EFFICIENCY OF CHROMIUM REMOVAL

\begin{tabular}{cccccccc}
\hline $\begin{array}{c}\text { Action } \\
\text { time(min) }\end{array}$ & 2 & 4 & 6 & 8 & 10 & 30 & 60 \\
\hline $\begin{array}{c}\text { Initial chromium } \\
\text { content(mg/L) } \\
\text { Chromium }\end{array}$ & 34.9 & 34.9 & 34.9 & 34.9 & 34.9 & 34.9 & 34.9 \\
$\begin{array}{c}\text { content after } \\
\text { treatment (mg/L) } \\
\text { Chromium }\end{array}$ & 94.75 & 0.38 & 0.27 & 0.18 & 0.18 & 0.17 & 0.17 \\
removal rate $(\%)$ & 6 & 9 & 2 & 6 & 0 & 4 & 6 \\
\hline
\end{tabular}

TABLE II. EFFECT OF PULSE VOLTAGE ON THE EFFICIENCY OF REMOVING CHROMIUM REMOVAL

\begin{tabular}{cccccc}
\hline $\begin{array}{c}\text { Pulse Voltage } \\
(\mathrm{V})\end{array}$ & 50 & 75 & 100 & 125 & 150 \\
\hline $\begin{array}{c}\text { Initial chromium } \\
\text { content (mg/L) } \\
\text { Chromium } \\
\text { content after } \\
\text { treatment (mg/L) } \\
\begin{array}{c}\text { Chromium } \\
\text { removal rate }(\%)\end{array}\end{array}$ & 0.296 & 34.9 & 34.9 & 34.9 & 34.9 \\
\hline
\end{tabular}

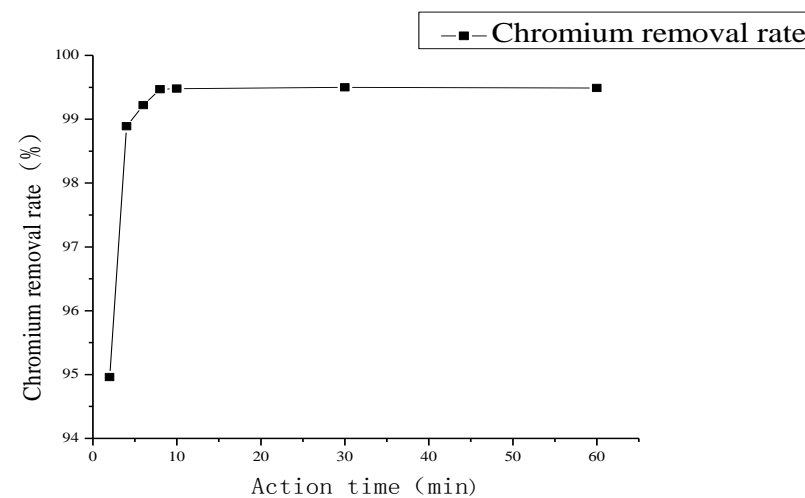

Figure 1. Chromium removal rate along with the change of action time.

From Table I, Figure 1 can be seen that the removal rate of chromium in wastewater with the increase with the time of action, After the action time reaches $4 \mathrm{~min}$, the rise tends to be flat, chromium removal rate gradually becoming stable. The removal rate of chromium in wastewater was $98.89 \%$ at $4 \mathrm{~min}$, the content of chromium in waste water was reduced from $34.9 \mathrm{mg} / \mathrm{L}$ to $0.386 \mathrm{mg} / \mathrm{L}$, and the chromium content was below the national emission standard. Although the removal rate of chromium is still increasing with the lengthening of time, the longer the action time is, the more energy is consumed, and the higher the time cost, the higher the production cost. Therefore, the best time for chromium removal should be $4 \mathrm{~min}$.

\section{B. The Influence of Different Pulse Voltage on Chromium Removal Efficiency}

Taking into account the pulse generator in the FET can withstand the current is limited, and the voltage is too high to conducive energy saving, the experimental pulse voltage is generally below $150 \mathrm{~V}$.

Take $1 \mathrm{~L}$ of water sample, adjust the $\mathrm{pH}$ to $3-4$, adjust the pulse width of $3 \mathrm{~ms}$, period of $30 \mathrm{~ms}$, the plate spacing of $20 \mathrm{~cm}$ and action time $4 \mathrm{~min}$. The pulse voltage was $50 \mathrm{~V}, 75 \mathrm{~V}$, $100 \mathrm{~V}, 125 \mathrm{~V}, 150 \mathrm{~V}$. After 30 seconds of electrification, $\mathrm{FeSO}_{4} \cdot 7 \mathrm{H}_{2} \mathrm{O}$ solution was added near the positive plate, the ratio was $m_{\mathrm{FeSO}_{4} \cdot 7 \mathrm{H}_{2} \mathrm{O}}: m_{\mathrm{Cr}^{6+}}=1: 1$.the end of the experiment, sampling detection. See Table II, Figure 2. 


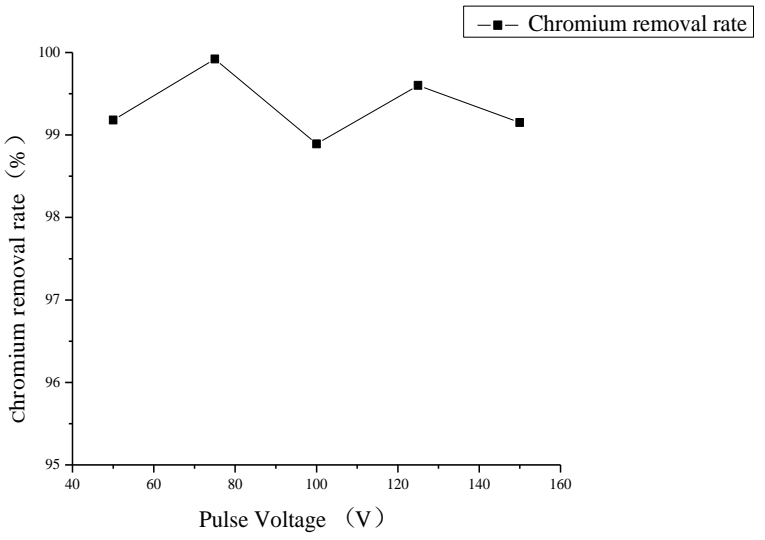

Figure 2. Chromium removal rate along with the change of Pulse Voltage.

From Table II, Figure 2 can be drawn: the choice of different pulse voltage, the water content of chromium in the national emission standards $1 \mathrm{mg} / \mathrm{L}$ below. Although the concentration of chromium after treatment fluctuates below $0.386 \mathrm{mg} / \mathrm{L}$, the treatment effect can be achieved. In the follow-up study, this experiment can be repeated for better analyzing towards the cause of the fluctuation. In the further experiments, $75 \mathrm{~V}$ was chosen as the optimum voltage parameter.

\section{The Influence of Different Duty Ratio on Chromium Removal Efficiency}

Duty cycle is the ratio of the pulse width to the period of the pulsed electric field. In order to select the ideal reaction condition, the duty cycle is chosen as the experimental factor. The action time is $4 \mathrm{~min}$, the pulse voltage is $75 \mathrm{~V}$.

Take $1 \mathrm{~L}$ of water sample, and the $\mathrm{pH}$ value was adjusted to $3-4$, and period of $30 \mathrm{~ms}$. The distance between the plates was $20 \mathrm{~cm}$ and the duty cycle was $10 \%, 20 \%, 30 \%, 40 \%$ and $50 \%$ respectively. After 30 seconds of electrification, $\mathrm{FeSO}_{4} \cdot 7 \mathrm{H}_{2} \mathrm{O}$ solution was added near the positive plate, the ratio was

$m_{\mathrm{FeSO}_{4} \cdot 7 \mathrm{H}_{2} \mathrm{O}}: m_{\mathrm{Cr}^{6+}}=1: 1$.After the end of the experiment, samples were taken for testing. See Table III, Figure 3.

TABLE III. EFFECT OF DUTY RATIO ON THE EFFICIENCY OF REMOVING CHROMIUM REMOVAL

\begin{tabular}{cccccc}
\hline Duty Ratio & $10 \%$ & $20 \%$ & $30 \%$ & $40 \%$ & $50 \%$ \\
\hline $\begin{array}{c}\text { Initial chromium } \\
\text { content (mg/L) }\end{array}$ & 34.9 & 34.9 & 34.9 & 34.9 & 34.9 \\
$\begin{array}{c}\text { Chromium content } \\
\text { after treatment (mg/L) }\end{array}$ & 0.028 & 0.216 & 0.328 & 0.360 & 0.350 \\
$\begin{array}{c}\text { Chromium removal } \\
\text { rate (\%) }\end{array}$ & 99.92 & 99.38 & 99.06 & 98.97 & 99.00 \\
\hline
\end{tabular}

[1] L. Lamport, LaTeX, A Document Preparation System, 2nd edn. (Addison-Wesley, Reading, MA, 1994).

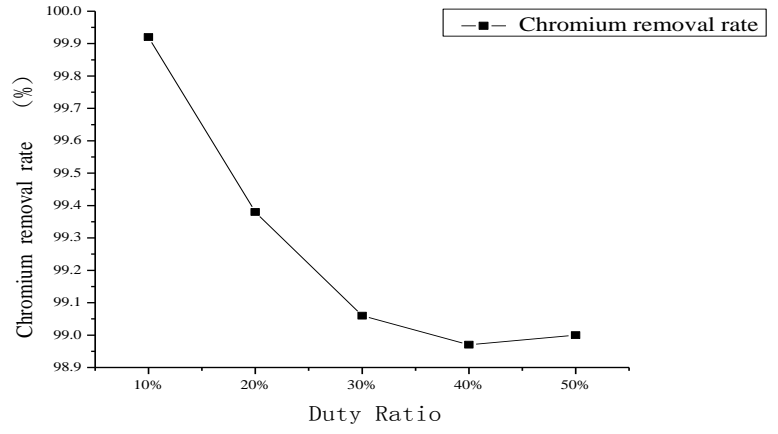

Figure 3. Chromium removal rate along with the change of Duty Ratio.

As can be seen from Table III, Figure 3, the chromium content in wastewater after treatment and duty cycle is closely related. In the same period, the smaller the duty cycle, pulse width is narrower, the role of an electric field within a shorter period of time, the higher the removal rate of chromium. This is because the smaller the duty cycle is, the smaller the solution concentration difference polarization is conducive to the diffusion, promote the removal of chromium, but also reduces energy consumption. the best duty cycle for chromium removal should be $10 \%$.this time the removal rate of chromium $99.92 \%$.

\section{SUMMARY}

In this paper, the pulsed electric field-coprecipitation method was used to study the removal of chromium from high chromium industrial wastewater, and the removal efficiency of chromium was discussed. The action time, pulse voltage and duty cycle on the removal of chromium were studied. Concluded as follow:

1.Pulsed electric field-coprecipitation method is a kind of efficient chromium removal method. When the action time is $4 \mathrm{~min}$, the pulse voltage is $75 \mathrm{~V}$ and the duty ratio is $10 \%$, the content of $\mathrm{Cr}$ in the wastewater decreases from $34.9 \mathrm{mg} / \mathrm{L}$ to $0.028 \mathrm{mg} / \mathrm{L}$. Chromium removal rate of up to $99.92 \%$, to the national emission standards.

2. Treatment of high chromium industrial waste water by pulsed electric field-coprecipitation method. The chromium content in treated wastewater decreased with the increase of working time, and the removal rate of chromium was increased.

3. Pulsed electric field-coprecipitation method has not yet been reported in domestic and foreign literatures, which provides new ideas and new methods for the treatment of industrial high chromium wastewater.

\section{ACKNOWLEDGMENTS}

This work was supported by Yunnan Province Department of Education Fund under Grant No.2014Y019 and2013Y356 and Yunnan Uniwersity Fund under Grant No.2014CG005 and No.2014CG011.

\section{REFERENCES}


[2] AMS, AMS-LaTeX Version 2 User's Guide (American Mathematical Society, Providence, 2004), http://www.ams.org/tex/amslatex. html.

[3] C. Jarlskog, CP Violation (World Scientific, Singapore, 1988).

[4] B. W. Bestbury, R-matrices and the magic square, J. Phys. A 36, 1947 (2003).

[5] P. X. Deligne and B. H. Gross, On the exceptional series, and its descendants, C. R. Math. Acad. Sci. Paris 335, 877 (2002).

[6] J. M. Landsberg and L. Manivel, Triality, exceptional Lie algebras and Deligne dimension formulas, Adv. Math. 171, 59 (2002), http://www. url.com/triality.html.

[7] G. H. Weiss (ed.), Contemporary Problems in Statistical Physics (SIAM, Philadelphia, 1994).

[8] R. K. Gupta and S. D. Senturia, Pull-in time dynamics as a measure of absolute pressure, in Proc. IEEE Int. Workshop on Microelectromechanical Systems (MEMS'97), (Nagoya, Japan, 1997).

[9] L. F. Richardson, Arms and Insecurity (Boxwood, Pittsburg, 1960).

[10] R. V. Churchill and J. W. Brown, Complex Variables and Applications, 5th edn. (McGraw-Hill, 1990).

[11] F. Benhamou and A. Colmerauer (eds.), Constraint Logic Programming, Selected Research (MIT Press, 1993).
[12] D. W. Baker and N. L. Carter, Seismic Velocity Anisotropy Calculated for Ultramafic Minerals and Aggregates, in Flow and Fracture of Rocks, eds. H. C. Heard, I. V. Borg, N. L. Carter and C. B. Raleigh, Geophys. Mono., Vol. 16 (Am. Geophys. Union, 1972), pp. $157-166$.

[13] J. D. Hobby, A User's Manual for MetaPost, Tech. Rep. 162, AT\&T Bell Laboratories (Murray Hill, New Jersey, 1992).

[14] B. W. Kernighan, PIC-A Graphics Language for Typesetting, Computing Science Technical Report 116, AT\&T Bell Laboratories (Murray Hill, New Jersey, 1984).

[15] H. C. Heard, I. V. Borg, N. L. Carter and C. B. Raleigh, VoQS: Voice Quality Symbols, Revised to 1994, (1994).

[16] M. E. Brown, An interactive environment for literate programming, PhD thesis, Texas A\&M University, (TX, USA, 1988), pp. ix + 102.

[17] G. S. Lodha, Quantitative interpretation of ariborne electromagnetic response for a spherical model, Master's thesis, University of Toronto (1974).

[18] D. Jones, The term 'phoneme', in Phonetics in Linguistics: A Book of Reading, eds. W. E. Jones and J. Laver (Longman, London, 1973) pp. 187-204.

[19] B. Davidsen, Netpbm (1993), ftp://ftp.wustl.edu/graphics/ graphics/packages/NetPBM. 